\title{
Low Expression of miR-448 Induces EMT and Promotes Invasion by Regulating ROCK2 in Hepatocellular Carcinoma
}

\author{
Huaqiang Zhu Xu Zhou Chaoqun Ma Hong Chang Hongguang Li \\ Fangfeng Liu Jun Lu
}

Department of Hepatobiliary Surgery, Provincial Hospital Affiliated to Shandong University (East

District), Jinan, China

\section{Key Words}

miR-448 • ROCK2 $•$ EMT $・$ Invasion $・ H C C$

\begin{abstract}
Background/Aims: miR-448 has been reported to exhibit abnormal expression in hepatocellular carcinoma (HCC), however, the essential role of miR-448 in HCC progression is still unclear. Methods: real-time PCR was used to detect the expression of miRNAs and candidate genes in HCC samples $(n=117)$. miR-448 mimics and inhibitor were tansfected in human HCC cells. The transwell assay was used to examine the cell invasive ability. The regulation mechanism was confirmed by luciferase reporter assay. The markers of EMT were detected by using Western blot. Results: miR-448 was decreased in HCC samples and associated with HCC development. Inhibition of miR-448 significantly promoted cell invasion, while the effect of miR-448 up-regulation was reverse. miR-448 could regulate ROCK2 in hepatocellular carcinoma. Knockdown of ROCK2 expression partially reversed the effect of miR-448 inhibitor. Abnormal expression of miR-448 could regulate the markers of epithelialmesenchymal transition (EMT). Conclusions: miR-448 may contribute to the progression of $\mathrm{HCC}$ via regulating ROCK2 expression.
\end{abstract}

H. Zhu and X. Zhou contributed equally to this work.

Jun Lu

KARGER 125
Department of Hepatobiliary Surgery, Provincial Hospital Affiliated to Shandong University, NO.9677 Jingshi Road, Jinan, 250014, Shandong Province (China) Tel. +86-531-68773229, Fax +86-531-68773233, E-Mail lujunqilu@126.com 


\section{Cellular Physiology Cell Physiol Biochem 2015;36:487-498

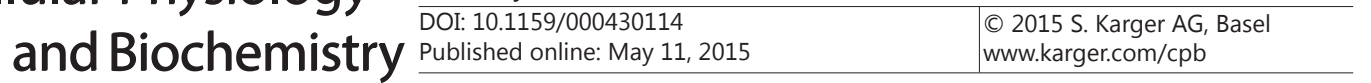 Zhu et al.: MiR-448 Induces EMT by Regulating ROCK2 in HCC}

\section{Introduction}

Hepatocellular carcinoma (HCC) is one of malignant cancers worldwide and the third leading cause of cancer-related death [1]. Despite many strategies have been used to treat HCC, the average 5-year overall survival remains low [2], because of the cancer cells metastasis. However, the complicated molecular and cellular mechanisms of HCC development are not unclear. Therefore, elucidating the potential molecular mechanism of tumor development and identify the therapeutic targets would improve the therapy of HCC.

microRNAs (miRNAs) were identified as an abundant class of small non-coding RNAs that regulated different biological processes of tumors by binding to target gene 3 '-untranslated regions (UTRs) [3]. Growing evidence has shown that miRNAs play crucial roles in various physiological processes and are involved in the initiation and progression of HCC [4-8]. A recent study had identified the pathogenesis-related microRNAs in HCC by expression profiling, which showed miR-448 was down-regulated in 40 HCC samples and served as a novel biomarker for HCC [9]. However, the underlying role of miR-448 in the development of HCC is not explored.

Rho-associated coiled-coil-containing protein kinase 2 (ROCK2) belongs to a family of serine/threonine kinases, which are activated via interaction with Rho GTPases [10]. An increasing number of studies reported that ROCK2 is involved in the development of the malignant tumors. Up-regulation of ROCK2 expression is implicated in poor prognosis in different human cancers, including breast cancer and lung cancer [11,12]. ROCK2 plays a key role in HCC invasion and metastasis $[13,14]$. For example, in vitro and in vivo, up-regulation of ROCK2 in HCC is obviously involved in the presence of tumor microsatellite formation, and down-regulation of ROCK2 inhibited HCC migration and invasion [2].

In our study, we demonstrated that miR-448 was down-regulated in HCC samples compared with corresponding adjacent tissues, and the expression analyses exhibited a significantly negative correlation. We first found that miR-448 was related to tumor stage and metastasis of HCC. In addition, we identified that miR-448 could regulate the HCC cells invasion by regulating ROCK2. Moreover, we also revealed that miR-448 could regulate the markers of EMT in HCC cells.

\section{Materials and Methods}

\section{Clinical Tissues}

A total of 117 HCC samples were collected from the archives of the Provincial Hospital Affiliated to Shandong University (Jinan, China). Total patients had provided the written informed consent. The informed consent approval from the Shandong University Institute Research Ethics Committee was obtained.

\section{Cell culture, cell transfection and RNA interference}

Five HCC cell lines (HepG2, Hep3B, Huh-7, QSG-7701 and SMMC-7721) and a normal cell line (LO2) were cultured in DMEM Medium (Life Technologies, Carlsbad, CA, USA) supplemented with 10\% FBS (Life Technologies, Carlsbad, CA, USA), $100 \mathrm{U} / \mathrm{mL}$ penicillin, and $100 \mu \mathrm{g} / \mathrm{mL}$ streptomycin in a humidified atmosphere containing $5 \% \mathrm{CO}_{2}$ at $37^{\circ} \mathrm{C}$. We conducted the transfections by using a Lipofectamine $2000 \mathrm{kit}$ (Invitrogen, Carlsbad, CA, USA). Cell lines were transfected with miR-448 mimics or inhibitor (GenePharma, Shanghai, China). Short interfering RNA targeting ROCK2 (Santa Cruz Biotechnology, Santa Cruz, USA) were transfected into cells in 6-well plates using Lipofectamine 2000 reagent (Invitrogen, Carlsbad, USA) according to the manufacturer's instructions.

RNA isolation and real-time PCR

Isolation of total RNA from cells was performed using the miRVana miRNA Isolation Kit (Ambion, Austin, TX, USA). According to the manufacturer's instructions (Ambion, Austin, TX, USA), miR-448 was investigated using the miRVana real-time PCR miRNA Detection Kit and real-time PCR Primer Sets. The primers for real-time PCR were shown as below. miR-448: Forward primer: TTATTGCGATGTGTTCCTTATG, 


\section{Cellular Physiology Cell Physiol Biochem 2015;36:487-498 \begin{tabular}{l|l}
\hline DOI: $10.1159 / 000430114$ & (C) 2015 S. Karger AG, Basel
\end{tabular} \begin{tabular}{l|l} 
and Biochemistry Published online: May 11, 2015 & www.karger.com/cpb
\end{tabular} \\ Zhu et al.: MiR-448 Induces EMT by Regulating ROCK2 in HCC}

Reverse primer: ATGCATGCCACGGGCATATACACT; ROCK2: Forward primer: TCAGAGGTCTACAGATGAAGGC, Reverse primer: CCAGGGGCTATTGGCAAAGG. U6 small nuclear RNA was used for normalization. Real-time PCR assay was performed on ABI PRISM7500 system (Applied Biosystems, California, USA).

\section{Western blotting assay}

Total protein obtained from cultured cells was examined using a BCA Protein Assay Kit (Beyotime, Jiangsu, China). The blots were blocked in BSA (5\% w/v in PBS + 0.1\% Tween 20) at room temperature. The antibodies which are against ROCK2, Vimentin, and GAPDH were used according to the manufacturer's instructions, and were purchased from Santa Cruz Biotechnology (Santa Cruz, CA). The antibodies against $\mathrm{N}$-cadherin and E-cadherin were obtained in our previous study, which were purchased from Abcam (Cambridge, MA, USA). After using the secondary antibodies (Santa Cruz Biotechnology, Santa Cruz, USA) at 1:2,000 (v/v) dilutions in PBS + 0.1\% Tween 20 for $1 \mathrm{~h}$, the signals were shown using ECL kit (Thermo Scientific Pierce, Thermo Fisher Scientific, Rockford, USA).

\section{Cell proliferation assays}

We performed CCK-8 assays to investigate cells proliferation. According to the instructions, Cell Counting Kit-8 (CCK-8) (Dojindo, Tokyo, Japan) reagent was added at 0, 24, 48, and $72 \mathrm{~h}$ respectively after seeding $4 \times 10^{3}$ cells per well in a 96 -well plate, and incubated at $37^{\circ} \mathrm{C}$ for $2 \mathrm{~h}$. The $\mathrm{OD}$ (optical density) value was detected by using a microplate reader (Bio-Rad, Richmond, CA, USA).

\section{Apoptosis assay}

Cells apoptosis was measured in cells with an Annexin V assay kit (Miltenyi Biotec, Bergisch Gladbach, Germany). Annexin V-fluorescein isothiocyanate (FITC) and propidium iodide (PI) were added after treating cell according to the instructions. Then $300 \mu \mathrm{L}$ of $1 \times$ binding buffer was added. The flow cytometry with a FACS Calibur (BD Bioscience, San Jose, CA, USA) was performed to evaluate the result.

\section{Transwell invasion assay}

Cell invasion assays were performed with BioCoat Matrigel (BD Biosciences, San Jose, CA) and 8- $\mu$ m pore size invasion chambers (Millipore, Eschborn, Germany) according to the manufacturer's instructions [15]. After treatment, cells were harvested. Then, cells $\left(1 \times 10^{5}\right)$ were seeded into the upper chamber of a 24-well plate with serum-free medium. After $24 \mathrm{~h}$ incubation in $37^{\circ} \mathrm{C}$ and $5 \% \mathrm{CO}_{2}$, cells that remained on top of the filter were scrubbed off, and those that invaded the underside of the filter were fixed and stained with crystal violet. The images were acquired by using NIS Elements image analysis software (Nikon, Tokyo, Japan). For the membrane images, we measure the migrated cells using image analysis software ImagePro Plus 6.0 (Media Cybernetics, Bethesda, USA).

\section{Luciferase reporter assay}

Luciferase reporter assay was performed according to the manufacturer's protocol. 48 hours after transfection, luciferase activity was evaluated in Victor 1420 Multilabel Counter (Wallac, Finland) using Luciferase Assay System (Promega, USA).

\section{Bioinformatics Analysis}

We used the bioinformatics method to predict the potential targeting genes of miR-448. Strikingly, the three websites including microRNA.org (http://www.microrna.org/microrna/), miRDB (http://mirdb.org/ cgi-bin/), and TargetScan (http://www.targetscan.org/) database showed that ROCK2 was a candidate gene due to 3 '-UTR of ROCK2 binds to miR-448 with the high score.

\section{Statistical analysis}

miR-448 and ROCK2 expression levels in the clinical samples was investigated by using chi-square tests. All the histogram was evaluated by performing GraphPad Prism, version 4.0 (GraphPad Software, San Diego California, USA). Statistical analyses were performed using Stata. 11.0. $\mathrm{P}<0.05$ indicated statistically significant. 


\section{Cellular Physiology Cell Physiol Biochem 2015;36:487-498

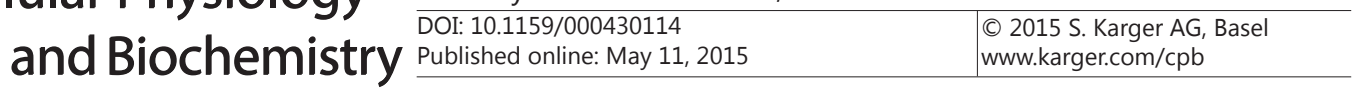 Zhu et al.: MiR-448 Induces EMT by Regulating ROCK2 in HCC}

\section{Results}

miR-448 and ROCK2 expression were negatively correlated in HCC tissues

The expression levels of miR-448 and ROCK2 were detected in 117 HCC samples and the corresponding adjacent tissues by real-time PCR. Strikingly, the results showed that miR-448 expression was lower in HCC tissues than that in corresponding adjacent tissues $(\mathrm{p}<0.05)$, whereas ROCK2 expression in tumor tissues was higher than that in corresponding adjacent tissues $(\mathrm{p}<0.05)$ (Fig. $1 \mathrm{~A}$ and $\mathrm{B}$ ). The scatter plots revealed that miR-448 and ROCK2 expression levels were negatively correlated in HCC tissues (Fig. 1C). All HCC tissues were divided into two groups using median mRNA level of miR-448 ( ${ }^{a}$ median $=0.3032$ ) and ROCK2 ( ${ }^{\mathrm{b}}$ median=3.0074) as threshold. The correlation between miR-448 expression and clinicopathological characteristics was shown as in Table 1 . There was significantly correlation with tumor stage $(\mathrm{p}=0.007)$ and metastasis $(\mathrm{p}=0.000)$. Thus, low expression level of miR-448 might contribute to the metastasis of HCC.

Table 1. Expression levels of miR-448 and ROCK2 in HCC and corresponding adjacent tissues. ${ }^{\mathrm{a}}$ median $=0.3032,{ }^{\mathrm{b}}$ median $=3.0074,{ }^{*}$ indicates $\mathrm{p}<0.05$

\begin{tabular}{|c|c|c|c|c|c|c|c|}
\hline Characteristics & $\begin{array}{c}\text { All } \\
\text { Patients }\end{array}$ & $\begin{array}{l}\text { miR-448 low } \\
\text { expression } \\
{ }^{\text {a }} \text { median }=0.3032\end{array}$ & $\begin{array}{l}\text { miR-448 high } \\
\text { expression } \\
{ }^{b} \text { median }=3.0074\end{array}$ & $\mathrm{p}$ & $\begin{array}{l}\text { ROCK2 low } \\
\text { expression }\end{array}$ & $\begin{array}{l}\text { ROCK2 high } \\
\text { expression }\end{array}$ & $\mathrm{p}$ \\
\hline $\mathrm{n}$ & 117 & 59 & 58 & & 58 & 59 & \\
\hline Age(yr) & & & & 0.642 & & & 0.924 \\
\hline$<60$ & 57 & 30 & 27 & & 28 & 29 & \\
\hline$\geq 60$ & 60 & 29 & 31 & & 30 & 30 & \\
\hline Sex & & & & 0.927 & & & 0.644 \\
\hline Male & 58 & 29 & 29 & & 30 & 28 & \\
\hline Female & 59 & 30 & 29 & & 28 & 31 & \\
\hline $\operatorname{AFP}(\mu \mathrm{g} / \mathrm{L})$ & & & & 0.783 & & & 0.519 \\
\hline$<200$ & 60 & 31 & 29 & & 28 & 32 & \\
\hline$\geq 200$ & 57 & 28 & 29 & & 30 & 27 & \\
\hline $\begin{array}{l}\text { Tumor size } \\
(\mathrm{cm})\end{array}$ & & & & 0.052 & & & 0.164 \\
\hline$<5$ & 56 & 23 & 33 & & 24 & 32 & \\
\hline$\geq 5$ & 61 & 36 & 25 & & 34 & 27 & \\
\hline TNM stage & & & & $0.007^{*}$ & & & $0.000^{*}$ \\
\hline $\mathrm{I}, \mathrm{II}$ & 50 & 18 & 32 & & 41 & 9 & \\
\hline III,IV & 67 & 41 & 26 & & 17 & 50 & \\
\hline Metastasis & & & & $0.000^{*}$ & & & $0.000^{*}$ \\
\hline No & 73 & 22 & 51 & & 48 & 25 & \\
\hline Yes & 44 & 37 & 7 & & 10 & 34 & \\
\hline
\end{tabular}
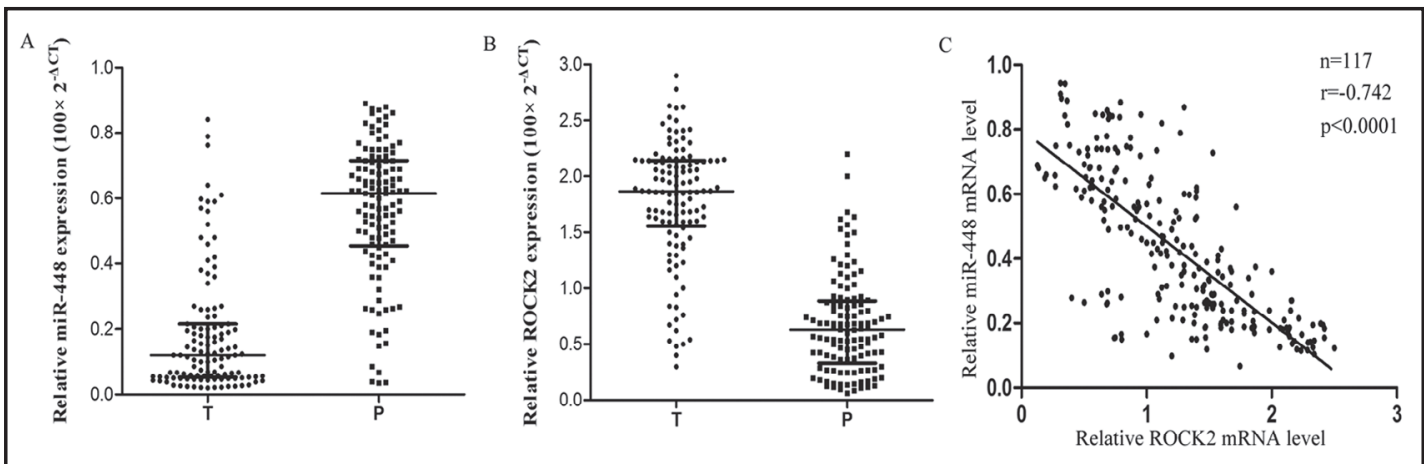

Fig. 1. miR-448 was reduced and ROCK2 was increased in HCC patients. A: Real-time PCR assay were used to detect miR-448 mRNA expression in HCC tissues (T) and corresponding adjacent tissues (P) (n=117, $\mathrm{p}<0.05$ ). B: The mRNA levels of ROCK2 relative to GAPDH in human HCC tissues (T) and corresponding adjacent tissues (P) were measured by using real-time PCR assay. C: The scatter plots revealed that miR-448 and ROCK2 expression levels were negatively correlated in HCC tissues ( $r=-0.742, p<0.0001)$. Data are represented as mean \pm SEM. * indicates $\mathrm{p}<0.05$. Two biological replicates for each sample were used for real-time PCR analysis and three technical replicates were analyzed for each biological replicate. 


\section{Cellular Physiology Cell Physiol Biochem 2015;36:487-498

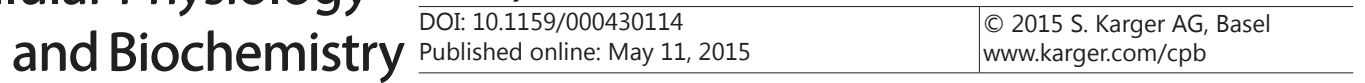

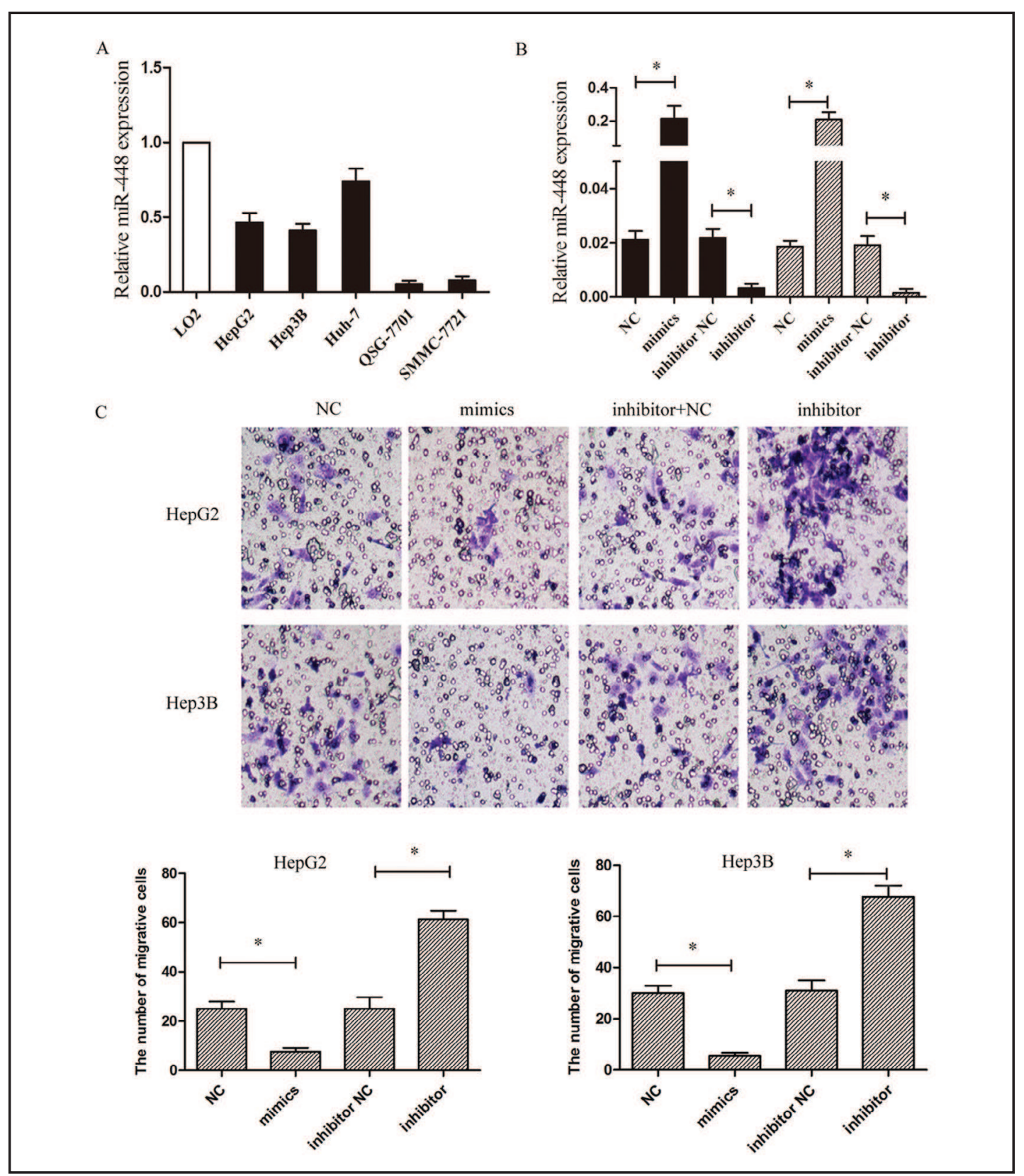

Fig. 2. miR-448 regulated cell lines invasion. A: The expression levels of miR-448 in five HCC cell lines (HepG2, Hep3B, Huh-7, QSG-7701 and SMMC-7721) and a normal cell line (LO2) relative to U6 were measured by real-time PCR. Two biological replicates for each sample were used for real-time PCR analysis and three technical replicates were analyzed for each biological replicate. Data are represented as mean \pm SEM. * indicates p<0.05. B: miR-448 expression level in cell lines transfected with miR-448 mimics, miR-448 inhibitor, control for miR-mimics (NC) and control for miR-448 inhibitor (inhibitor NC). The result was validated by real-time PCR. Two biological replicates for each sample were used for real-time PCR analysis and three technical replicates were analyzed for each biological replicate. Data are represented as mean \pm SEM. * indicates $\mathrm{p}<0.05$. C: Transwell assay was performed as described in Materials and Methods. HepG2 and Hep3B cells were transfected with NC, miR-448 mimics, inhibitor NC and miR-448 inhibitor for $24 \mathrm{~h}$. As shown, the representative images of invasive cells at the bottom of the membrane stained with crystal violet were visualized. For the membrane images, we measure the migrated cells using image analysis software ImagePro Plus 6.0 (Media Cybernetics, Bethesda, USA). The numbers of invading cells are shown in the lower panel $\left(\mathrm{n}=3\right.$ per condition). All data represent mean \pm SEM. ${ }^{*} \mathrm{p}<0.05$ by independent Student's $\mathrm{t}$-test. 


\section{Cellular Physiology Cell Physiol Biochem 2015;36:487-498 \begin{tabular}{l|l|l|} 
DOI: 10.1159/000430114 & (c) 2015 S. Karger AG, Bas
\end{tabular} \\ Zhu et al.: MiR-448 Induces EMT by Regulating ROCK2 in HCC}

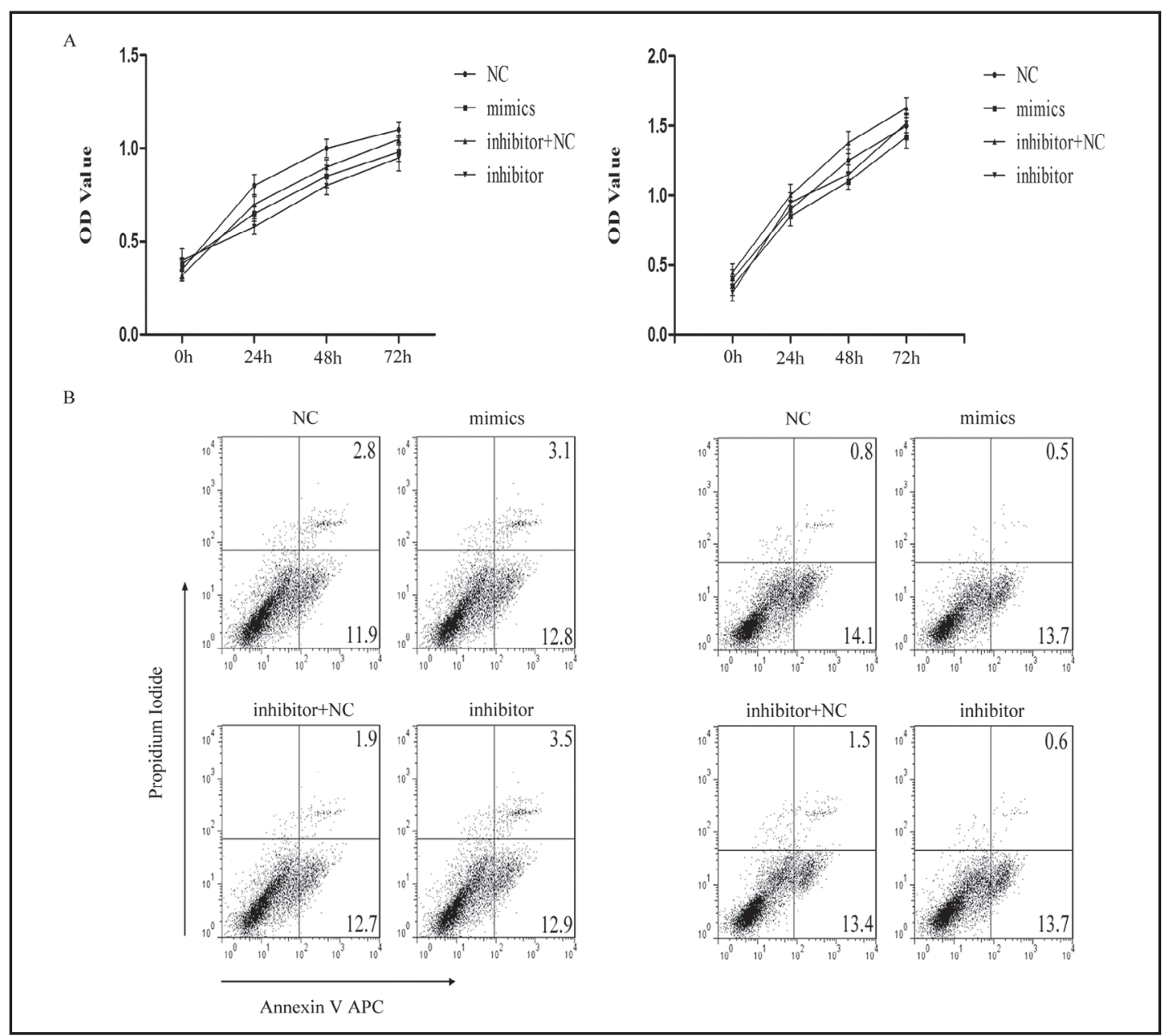

Fig. 3. miR-448 had no effect on cell lines proliferation and apoptosis. A: HepG2 (left) and Hep3B (right): Absorbance at $450 \mathrm{~nm}$ was presented with Mean \pm SEM. Two biological replicates for each sample were used for CCK-8 analysis and five technical replicates were analyzed for each biological replicate. All data represent mean \pm SEM. ${ }^{*}$ p $<0.05$ by independent Student's t-test. B: HepG2 (left) and Hep3B (right): Flow cytometry assay was performed to analysis cell apoptosis. Two biological replicates for each sample were used for the analysis and three technical replicates were analyzed for each biological replicate. All data represent mean \pm SEM. ${ }^{*}$ p $<0.05$ by independent Student's t-test.

Aberrant expression level of miR-448 was correlated with cell invasion

A recent study reported that miR-448 was reduced in HCC by using microarray [9], however, its roles in the development of HCC have not been elucidated. Here, to explore the potential role of miR-448 expression in HCC tumorigenesis, we detected the expression of miR-448 in five HCC cell lines (HepG2, Hep3B, Huh-7, QSG-7701 and SMMC-7721) and a normal cell line (LO2) by using real-time PCR. As shown in Fig. 2A, the expression of miR448 was reduced in all five cell lines, compared with the normal cell line. And the expression of miR-448 in HepG2 and Hep3B was between those in Huh-7 and in QSG-7701 (SMMC7721). Based on this expression pattern, we chose the HepG2 and Hep3B HCC cell lines to investigate the effect of miR-448. Cell lines were transfected with miR-448 negative control (NC), miR-448 mimics, miR-448 inhibitor negative control (inhibitor NC) and miR-448 inhibitor respectively. The transfection efficiency was validated by real-time PCR (Fig. 2B). Furthermore, using a Matrigel-coated transwell chamber, we found that overexpression of miR-448 suppressed cells invasion, whereas inhibition of miR-448 promoted the invasion ability of cells (Fig. 2C). This finding revealed that miR-448 might play an important role in regulate HCC metastasis. 


\section{Cellular Physiology Cell Physiol Biochem 2015;36:487-498 \begin{tabular}{ll|l} 
DOI: 10.1159/000430114 & O 2015 S. Karger AG, Bas
\end{tabular} \\ Zhu et al.: MiR-448 Induces EMT by Regulating ROCK2 in HCC}

A

ROCK2 3 'UTR Wild Type 5'... GAUAGACUAAGGAUAUAUGCAA . . .3' miR-448 ROCK2 3'UTR Mutant UACCCUGUAGGAUGUAUACGUU

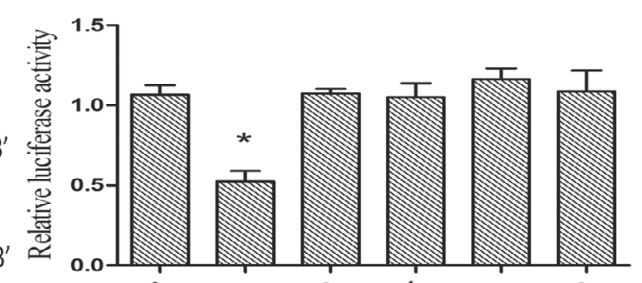

B

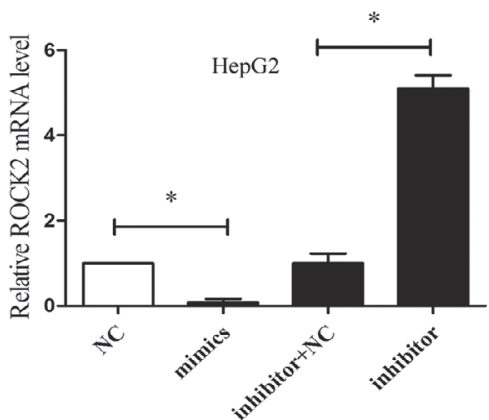

$\mathrm{NC}$ mimics inhibitor+NC inhibitor
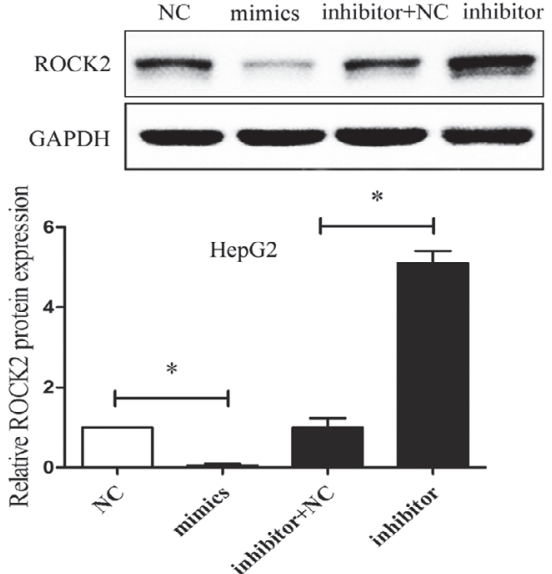
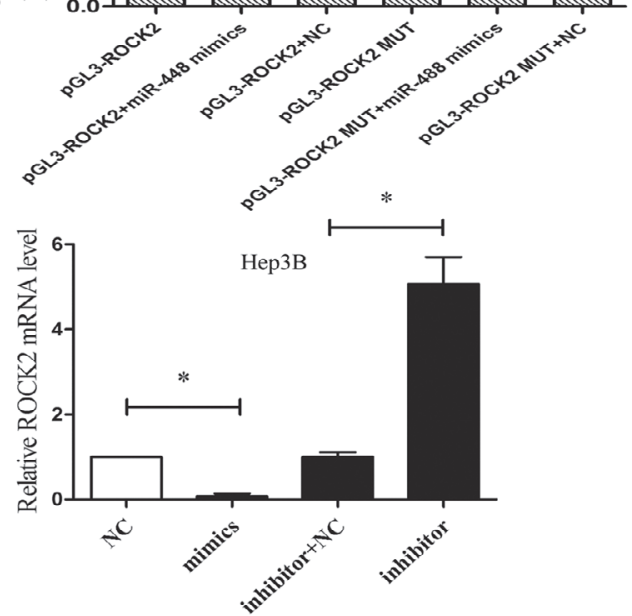

$\mathrm{NC}$ mimics inhibitor+NC inhibitor

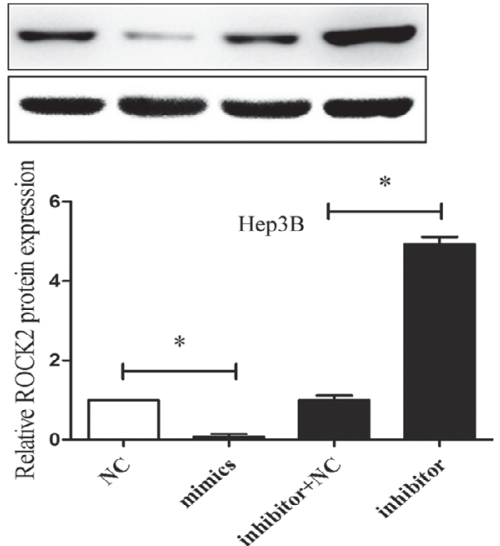

Fig. 4. miR-448 regulated ROCK2 expression. A: As shown, the potential miR-448 seed region at the 3'-UTR of ROCK2 mRNA was predicted by microRNA.org. HepG2 cells were co-transfected with miR-448 mimics (or NC) with pGL3-ROCK2 (or pGL3-ROCK2-MUT) vector. Luciferase activity was normalized by the ratio of firefly and Renilla luciferase signals. Two biological replicates for each sample were used for the analysis and three technical replicates were analyzed for each biological replicate. All data represent mean \pm SEM.*p $<0.05$ by independent Student's t-test. B: The mRNA and protein expression levels of ROCK2 in HepG2 and Hep3B cells transfected with NC, miR-448 mimics, inhibitor NC and miR-448 inhibitor were measured by real-time PCR and western-blotting assays. GAPDH level served as a loading control. The average values of integrated optical density (IOD) were assessed by analyzing five times and recorded in the histogram. The blots are representative of three independent experiments and quantification of independent experiments in lower panel. All data represent mean \pm SEM. ${ }^{*} \mathrm{p}<0.05$ by Student's t-test.

miR-448 had no effect on cell proliferation and apoptosis

In addition, to explore whether miR-448 could regulate HCC cell lines proliferation and apoptosis, we performed CCK-8 and apoptosis assays. The CCK-8 assay test showed no distinct differences on proliferation after manipulation of miR-448 in cells at 24-hour, 48- 


\section{Cellular Physiology Cell Physiol Biochem 2015;36:487-498 \begin{tabular}{l|l|l} 
DOI: 10.1159/000430114 & O 2015 S. Karger AG, Basel
\end{tabular} and Biochemistry Published online: May 11, 2015 www.karger.com/cpb

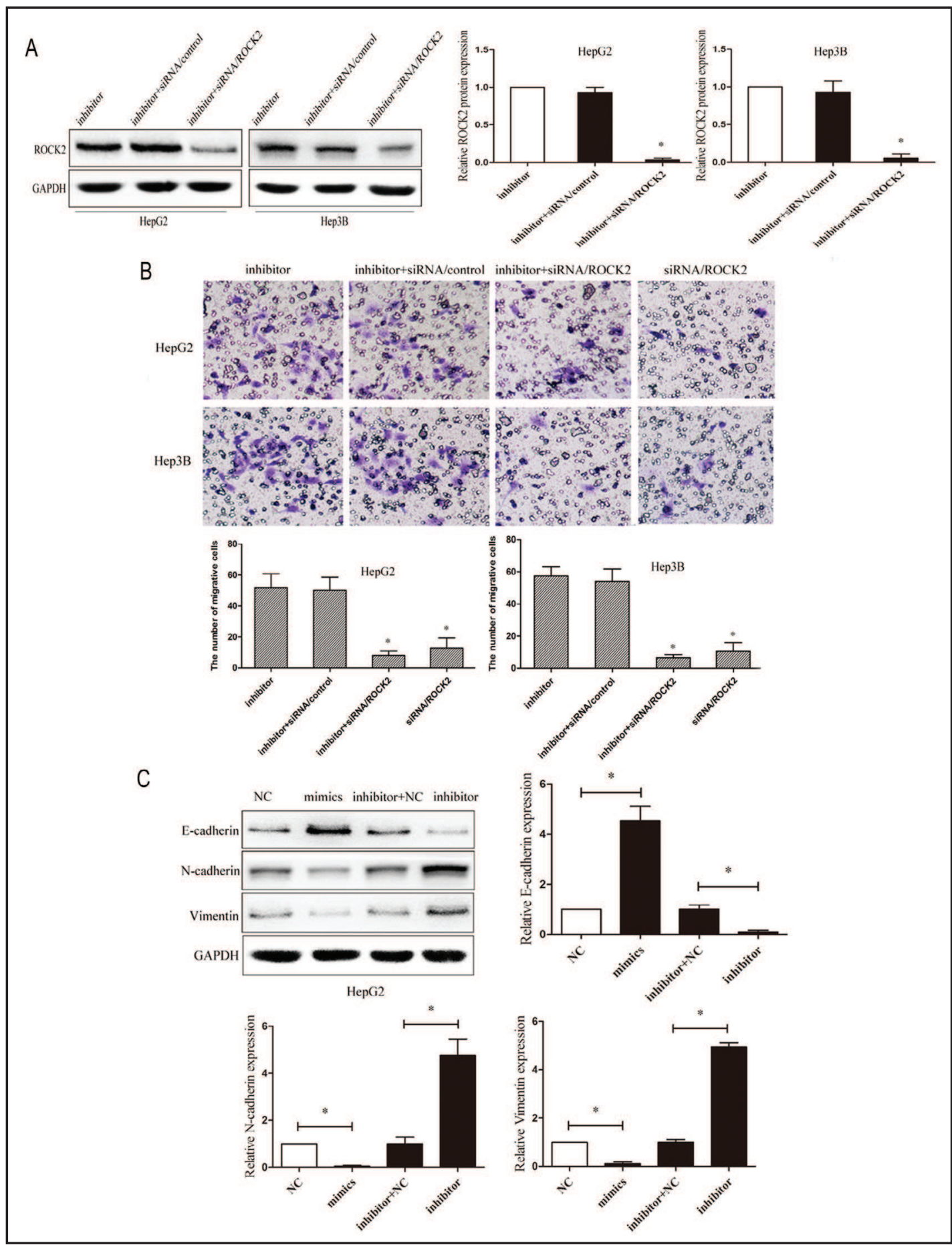

Fig. 5. Knockdown of ROCK2 abrogated the effect of miR-448 inhibition. A: Both HepG2 and Hep3B cells were co-transfected with miR-448 inhibitor and siRNA/ROCK2. The transfection cells of miR-448 inhibitor and the co-transfection cells of miR-448 inhibitor and siRNA/control were used as the control groups. The transfection efficiency was verified by using western blot assay. The blots are representative of three independent experiments and quantification of independent experiments in lower panel. All data represent mean \pm SEM. ${ }^{*} p<0.05$ by Student's t-test. B: According to the Materials and Methods, transwell assay was performed as shown. The representative images of invasive cells at the bottom of the membrane stained with crystal violet were visualized. For the membrane images, we measure the migrated cells using image analysis software ImagePro Plus 6.0 (Media Cybernetics, Bethesda, USA). The numbers of invading cells are 


\section{Cellular Physiology Cell Physiol Biochem 2015;36:487-498 \\ \begin{tabular}{ll|l} 
and Bioch $10.1159 / 000430114$ & $\begin{array}{l}\text { C } 2015 \mathrm{~S} \text {. Karger AG, Basel } \\
\text { www.karger.com/cpb }\end{array}$ \\
\hline
\end{tabular}}

shown in the lower panel ( $\mathrm{n}=3$ per condition). All data represent mean $\pm \mathrm{SEM} .{ }^{*} \mathrm{p}<0.05$ by independent Student's t-test. C: E-cadherin, N-cadherin and Vimentin protein expression levels in HepG2 cells transfected with NC, miR-448 mimics, inhibitor NC, and miR-448 inhibitor were detected by using western-blotting assay. GAPDH level served as a loading control. The blots are representative of three independent experiments and quantification of independent experiments in right panel. All data represent mean \pm SEM. ${ }^{*} \mathrm{p}<0.05$ by Student's t-test.

hour, and 72-hour time points (Fig. 3A). And there was no obvious difference in the apoptosis assay (Fig. 3B). These findings indicated that miR-448 had no effect on cell proliferation and apoptosis in vitro.

miR-448 could regulate ROCK2 in HCC cells

As described in the Methods, the target genes of miR-448 were predicted by online miRNA target prediction algorithms. We found that ROCK2, which had been reported to promote the invasion and metastasis of hepatocellular carcinoma [16] has the binding site. Then, to identify whether miR-448 could bind to ROCK2 mRNA, we cloned the 3'-UTR fragment involving in the predicted site into pGL3 luciferase reporter vector, named pGL3ROCK2. We also cloned the 3'-UTR fragment containing mutant sequence as a control group, named pGL3-ROCK2-MUT in the predicted target site. Interestingly, the luciferase reporter showed that the luciferase activity reduced in HepG2 cells with miR-448 mimics and pGL3ROCK2 vectors. However, miR-448 mimics did not have any effect on luciferase activity when target cells were transfected with pGL3-ROCK2-MUT vector (Fig. 4A). To further identify the regulatory effect of miR-448 on ROCK2, we performed real-time PCR and western blot assays to detect the mRNA and protein expression levels of ROCK2 responses to the changes of miR-448 expression. The assays showed a negative regulatory effect of miR-448 on ROCK2 both in mRNA and protein expression levels (Fig. 4B). Overexpression of miR-448 could reduce ROCK2 expression; meanwhile, inhibition of miR-448 could increase the expression of ROCK2. In sum, these results implied that miR-448 could regulate ROCK2 expression by binding its 3 '-UTR. These data suggested that miR-448 regulated ROCK2 in HCC cells.

Knockdown of ROCK2 partly reversed the effect of miR-448 inhibition

In addition, as shown in the previous results, ROCK2 was up-regulated in cells which were transfected with miR-448 inhibitor. Therefore, we silenced the expression of ROCK2 by RNA interference (data not shown). Cells were co-transfected with miR-448 inhibitor and siRNA/ROCK2. The transfection cells of miR-448 inhibitor and the co-transfection cells of miR-448 inhibitor and siRNA/control were the control groups. The transfection efficiency was confirmed by using western blot assay (Fig. 5A). ROCK2 expression was obviously lower in cells both co-transfected with miR-448 inhibitor and siRNA/ROCK2 than that in the control groups. Moreover, the transwell invasion assay revealed that the invasive ability indeed reversed to some extent when ROCK2 down-regulation in cells transfected with miR448 inhibitor compared to the control groups (Fig. 5B). These results indicated that the functional effect of miR-448 on HCC cell lines depends on ROCK2.

miR-448 could regulate the markers of EMT

Moreover, we performed western blot assay to explore whether miR-448 could regulate the molecular changes of EMT in HCC cell lines, the expression of mesenchymal markers, including $\mathrm{N}$-cadherin and Vimentin and the epithelial marker, E-cadherin. Thus, HepG2 cells were transfected with NC, miR-448 mimics, inhibitor NC and miR-448 inhibitor. In the protein expression level, up-regulated miR-448 expression promoted E-cadherin expression and decreased $\mathrm{N}$-cadherin and Vimentin expression. Meanwhile, down-regulated miR448 expression decreased E-cadherin expression and promoted N-cadherin and Vimentin expression (Fig. 5C). This result suggested that miR-448 could regulate the molecular changes of EMT in HCC. 


\section{Cellular Physiology Cell Physiol Biochem 2015;36:487-498 \\ \begin{tabular}{l|l} 
and Biochemistry $10.1159 / 000430114$ & $\begin{array}{l}\text { Dublished online: May 11, } 2015 \\
\text { Put. } 2015 \text { S. Karger AG, Basel } \\
\text { www.karger.com/cpb }\end{array}$ \\
\hline
\end{tabular} \\ Zhu et al:: MiR-448 Induces EMT by Regulating ROCK2 in HCC}

\section{Discussion}

HCC is a prevalent malignancy in the world. Cancer metastases are a major factor in the mortality of HCC patients. Aberrant expression of miRNAs plays a critical role in the different cancers development and progression through modulating oncogenic and tumor suppressor pathways [17-19]. Specifically for HCC, it is already reported that miRNAs are implicated in the cells apoptosis, prognosis, proliferation and invasion [20, 21]. For example, miR-486, which is frequently downregulated in HCC, inhibits HCC progression by targeting p85 $\alpha$ and PI3K-AKT activation [22].

In the present study, we focused on the mechanism of miR-448 in HCC invasion. The expression level of miR-448 was reduced in HCC. Meanwhile, ROCK2 expression was increased in HCC. To better understand the mechanisms of miR-448 in HCC cell invasion, we identified that miR-448 regulated ROCK2 in HCC using a bioinformatics method. Recently, some studies reported that ROCK2 was frequently overexpressed in human HCC and was closely associated with tumor microsatellite formation, a pathologic feature of intrahepatic metastasis. And ROCK2 promoted HCC migration and invasion both in vitro and in vivo. Using transwell invasion assay, we found that inhibition of miR-448 promoted HCC cells invasion, whereas up-regulation of miR-448 inhibited HCC cells invasion. Furthermore, the CCK-8 and apoptosis assays showed that miR-448 could not regulate the proliferation and apoptosis in HCC cells in vitro.

Growing evidence showed that EMT is involved in migration, tumor invasion and dissemination [23-25]. Decreased E-cadherin and elevated Vimentin and N-cadherin expression is one hallmark of EMT [26]. An increasing studies established functional associations between microRNAs and key effectors of EMT occurring in the context of carcinogenesis and embryonic development, such as miR-200 [27] and miR-10b [28]. In our study, high expression of miR-448 resulted in increased E-cadherin expression and decreased $\mathrm{N}$-cadherin and Vimentin expression. Meanwhile, knockdown miR-448 expression caused decreased E-cadherin expression and increased $\mathrm{N}$-cadherin and Vimentin expression.

Taken together, we identified a critical oncomiR, miR-448, that is frequently lowexpressed in HCC. Meanwhile, we found the inverse expression levels of miR-448 and ROCK2, both of which were related to tumor stage and metastasis. Mechanistically, we suggested that miR-448 inhibited HCC cells invasion by suppressing ROCK2 by binding of its 3'-UTR. As the limit on the number of HCC samples, more elaborate studies will be necessary for further exploration of the underlying role of miR-448 in the development of HCC. In future, miR-448 may be a therapeutic target in HCC.

\section{Abbreviations}

HCC (hepatocellular carcinoma); UTR (untranslated region); siRNA (small interfering RNA); EMT (epithelial-mesenchymal transition); CCK-8 (Cell Counting Kit-8).

\section{Disclosure Statement}

None declared.

\section{Acknowledgments}

This study was supported by Natural Science Foundation of Shandong Province in China (Y2008C22 and ZR2014HM099), Excellent Youth Scientist Foundation of Shandong Province in China (2007BS03038), and others of Shandong Province (2014WS0093, 2014GGB14041, 2014WS0095 and 2014WS0096). 


\section{Cellular Physiology Cell Physiol Biochem 2015;36:487-498 \begin{tabular}{c|l}
\hline DOI: 10.1159/000430114 & (c) 2015 S. Karger AG, Basel
\end{tabular} \begin{tabular}{l|l} 
and Biochemistry Published online: May 11, 2015 & www.karger.com/cpb
\end{tabular}}

\section{References}

1 El-Serag HB, Rudolph KL: Hepatocellular carcinoma: Epidemiology and molecular carcinogenesis. Gastroenterology 2007;132:2557-2576.

2 Perz JF, Armstrong GL, Farrington LA, Hutin YJ, Bell BP: The contributions of hepatitis b virus and hepatitis c virus infections to cirrhosis and primary liver cancer worldwide. J Hepatol 2006;45:529-538.

3 Bartel DP: Micrornas: Genomics, biogenesis, mechanism, and function. Cell 2004;116:281-297.

4 Esquela-Kerscher A, Slack FJ: Oncomirs - micrornas with a role in cancer. Nat Rev Cancer 2006;6:259-269.

5 Hanahan D, Weinberg RA: Hallmarks of cancer: The next generation. Cell 2011;144:646-674.

6 Yang XW, Shen GZ, Cao LQ, Jiang XF, Peng HP, Shen G, Chen D, Xue P: Microrna-1269 promotes proliferation in human hepatocellular carcinoma via downregulation of foxo1. BMC cancer 2014;14:909.

7 Zhou J, Lu S, Yang S, Chen H, Shi H, Miao M, Jiao B: Microrna-127 post-transcriptionally downregulates sept7 and suppresses cell growth in hepatocellular carcinoma cells. Cell Physiol Biochem 2014;33:15371546.

8 Li H, Li Y, Liu D, Sun H, Liu J: Mir-224 is critical for celastrol-induced inhibition of migration and invasion of hepatocellular carcinoma cells. Cell Physiol Biochem 2013;32:448-458.

9 Katayama Y, Maeda M, Miyaguchi K, Nemoto S, Yasen M, Tanaka S, Mizushima H, Fukuoka Y, Arii S, Tanaka $\mathrm{H}$ : Identification of pathogenesis-related micrornas in hepatocellular carcinoma by expression profiling. Oncol Lett 2012;4:817-823.

10 Liu T, Yu X, Li G, Yuan R, Wang Q, Tang P, Wu L, Liu X, Peng X, Shao J: Rock2 regulates cdc25a through ubiquitin proteasome system in hepatocellular carcinoma cells. Exp Cell Res 2012;318:1994-2003.

11 Kalender ME, Demiryurek S, Oztuzcu S, Kizilyer A, Demiryurek AT, Sevinc A, Dikilitas M, Yildiz R, Camci C: Association between the thr431asn polymorphism of the rock2 gene and risk of developing metastases of breast cancer. Oncol Res 2010;18:583-591.

12 Vigil D, Kim TY, Plachco A, Garton AJ, Castaldo L, Pachter JA, Dong H, Chen X, Tokar B, Campbell SL, Der CJ: Rock1 and rock2 are required for non-small cell lung cancer anchorage-independent growth and invasion. Cancer Res 2012;72:5338-5347.

13 Wong CC, Wong CM, Tung EK, Man K, Ng IO: Rho-kinase 2 is frequently overexpressed in hepatocellular carcinoma and involved in tumor invasion. Hepatology 2009;49:1583-1594.

14 Wong CC, Wong CM, Tung EK, Au SL, Lee JM, Poon RT, Man K, Ng IO: The microrna mir-139 suppresses metastasis and progression of hepatocellular carcinoma by down-regulating rho-kinase 2 . Gastroenterology 2011;140:322-331.

15 Zhang Z, Zhang Y, Sun XX, Ma X, Chen ZN: Microrna-146a inhibits cancer metastasis by downregulating vegf through dual pathways in hepatocellular carcinoma. Mol Cancer 2015;14:5.

16 Huang D, Du X, Yuan R, Chen L, Liu T, Wen C, Huang M, Li M, Hao L, Shao J: Rock2 promotes the invasion and metastasis of hepatocellular carcinoma by modifying mmp2 ubiquitination and degradation. Biochem Biophys Res Commun 2014;453:49-56.

17 Shi L, Zhang S, Wu H, Zhang L, Dai X, Hu J, Xue J, Liu T, Liang Y, Wu G: Mir-200c increases the radiosensitivity of non-small-cell lung cancer cell line a549 by targeting vegf-vegfr2 pathway. PloS one DOI: 10.1371/journal.pone.0078344

18 Lewis H, Lance R, Troyer D, Beydoun H, Hadley M, Orians J, Benzine T, Madric K, Semmes OJ, Drake R, Esquela-Kerscher A: Mir-888 is an expressed prostatic secretions-derived microrna that promotes prostate cell growth and migration. Cell Cycle 2014; 13:227-239.

19 Kim J, Wu L, Zhao JC, Jin HJ, Yu J: Tmprss2-erg gene fusions induce prostate tumorigenesis by modulating microrna mir-200c. Oncogene 2014; 33:5183-5192.

20 Akanuma N, Hoshino I, Akutsu Y, Murakami K, Isozaki Y, Maruyama T, Yusup G, Qin W, Toyozumi T, Takahashi M, Suito H, Hu X, Sekino N, Matsubara H: Microrna-133a regulates the mrnas of two invadopodia-related proteins, fscn1 and mmp14, in esophageal cancer. Br J Cancer 2014; 110:189-198.

21 Yu X, Li H, Jiang X, Guo L, Jiang W, Lu SH: Mir-203 inhibits the proliferation and self-renewal of esophageal cancer stem-like cells by suppressing stem renewal factor bmi-1. Stem Cells Dev 2014; 23:576-585.

22 Huang XP, Hou J, Shen XY, Huang CY, Zhang XH, Xie YA, Luo XL: Microrna-486-5p, downregulated in hepatocelluar carcinoma, suppresses tumor growth by targeting p85alpha. FEBS J 2015; 282:579-594. 
23 Yuan XW, Wang DM, Hu Y, Tang YN, Shi WW, Guo XJ, Song JG: Hepatocyte nuclear factor 6 suppresses the migration and invasive growth of lung cancer cells through p53 and the inhibition of epithelialmesenchymal transition. J Biol Chem 2013; 288:31206-31216.

24 Ye J, Wu D, Shen J, Wu P, Ni C, Chen J, Zhao J, Zhang T, Wang X, Huang J: Enrichment of colorectal cancer stem cells through epithelial-mesenchymal transition via cdh1 knockdown. Mol Med Rep 2012; 6:507-512.

25 Shi L, Jackstadt R, Siemens H, Li H, Kirchner T, Hermeking H: P53-induced mir-15a/16-1 and ap4 form a double-negative feedback loop to regulate epithelial-mesenchymal transition and metastasis in colorectal cancer. Cancer Res 2014; 74:532-542.

26 Kitamura K, Seike M, Okano T, Matsuda K, Miyanaga A, Mizutani H, Noro R, Minegishi Y, Kubota K, Gemma A: Mir-134/487b/655 cluster regulates tgf-beta-induced epithelial-mesenchymal transition and drug resistance to gefitinib by targeting magi2 in lung adenocarcinoma cells. Mol Cancer Ther 2014;13:444-453.

27 Paterson EL, Kazenwadel J, Bert AG, Khew-Goodall Y, Ruszkiewicz A, Goodall GJ: Down-regulation of the mirna-200 family at the invasive front of colorectal cancers with degraded basement membrane indicates emt is involved in cancer progression. Neoplasia 2013;15:180-191.

28 Ouyang H, Gore J, Deitz S, Korc M: Microrna-10b enhances pancreatic cancer cell invasion by suppressing tip30 expression and promoting egf and tgf-beta actions. Oncogene 2014; 33:4664-4674. 